www.jmscr.igmpublication.org

Index Copernicus Value: 79.54

ISSN (e)-2347-176x ISSN (p) 2455-0450

crossref DOI: https://dx.doi.org/10.18535/jmscr/v7i6.82

\title{
Epidemology of Intertrochanteric Fractures of femur in a tertiary care centre in North India
}

\author{
Authors
Dr Irfan Ul Ashraf ${ }^{1}$, Dr Abdul Ghani ${ }^{2}$ Dr Mudasir Rashid ${ }^{3}$, Dr Tanveer Ali ${ }^{4}$ \\ ${ }^{1,3,4}$ Resident, Orthopaedics Government Medical College Jammu \\ ${ }^{2}$ Associate Professor, Orthopaedics Government Medical College Jammu
}

\begin{abstract}
Introduction: Intertrochanteric fractures are seen with increasing frequency and severity as the life expectancy of our population increases. Intertrochanteric fracture accounts for nearly fifty percent of fractures of the hip. Intertrochanteric fractures in young are usually a result of high energy trauma.

Materials and Methods: Our study is a retrospective and prospective study conducted in Govt. Medical College Jammu from May 2017 to August 2018. Data recorded was analyzed in frequencies.

Results: Our study recorded 100 patients with intertrochanteric fractures of femur. Mean age of patients in our study was 74.77 years with Males affected more than females. Trivial fall being the most common mechanism of injury.

Conclusion: Intertrochanteric fractures are relatively common in our environment with higher incidence seen in elderly above 60 years of age. Skilled surgical fracture fixation, early mobilization of these patients reduces the morbidity and mortality rate.

Keywords: Intertrochanteric, hip, fractures.
\end{abstract}

\section{Introduction}

Intertrochanteric fractures represent the commonest fractures of hip especially in elderly with porotic bone (Grisso JA, et al 1991). Intertrochanteric fracture accounts for nearly fifty percent of fractures of the hip. They continue to be a major cause for disability resulting in reduced quality of life and also leading to death. It usually occurs due to low energy trauma like simple falls. The incidence of senile hip fractures has been rising due to increase in aging population in most parts of the world. Women are three times more liable to these types of fractures than men due to their wider pelvis and early osteoporosis. Intertrochanteric fractures in young are usually a result of high energy trauma.It has been suggested that these fracture types may have different risk factors .Low bone mineral density increases persons likelihood of sustaining a hip fracture in a fall and is a well established risk factor [Greenspan SL et al; 1994, Johnell O et al; 2005]. In particular trochanteric fractures are more closely associated with severe and generalized bone loss than fractures in cervical region. Patients with trochanteric fractures had significantly lower serum vitamin D levels compared with those with cervical hip fractures. [Dretakis OE et ; 2011]

The primary goal in the treatment of a patient with intertrochanteric fracture is to return the patient to 
his / her pre - fracture activity as early as possible. Rapid mobilization of patients reduces the morbidity and mortality rate. However due to number of factors management of trochanteric fractures pose a challenge to orthopaedic surgeons.

\section{Materials and Methods}

The Study was conducted at Government Medical College Hospital, Jammu on intertrochanteric fractures admitted in emergency and outpatient department from May 2017 to August 2018. All patients with intertrochanteric fractures on admission were subjected to initial resuscitation. Adequate fluids and analgesia was given at the time of admission. Abdomen, chest and head injuries were treated as a priority. Radiological evaluation of the patient was done in emergency department. Radiographs AP View of pelvis with both hips and AP and lateral views of injured side were taken. Skin traction was given to the patients prior to surgical procedure. Patients were operated at an average of 1 week after trauma, in routine theatre days by usual methods of fixation as per type of fracture and classifications (Boyd and Griffin, Evans, AO).

The data recorded was analyzed in frequencies.

\section{Results}

The following observations were made on 100 cases of intertrochanteric fractures at Government medical college Jammu from May 2017 to august 2018.

Table 1 shows majority of patients were older than 60 years of age.

Age distribution of Patients

\begin{tabular}{|l|c|c|c|}
\hline S .No. & Age group (years) & No. of cases & Percentage (\%) \\
\hline 1 & $21-30$ & 2 & $02 \%$ \\
\hline 2 & $31-40$ & 5 & $05 \%$ \\
\hline 3 & $41-50$ & 8 & $08 \%$ \\
\hline 4 & $51-60$ & 8 & $11 \%$ \\
\hline 5 & $61-70$ & 30 & $30 \%$ \\
\hline 6 & $71-80$ & 28 & $28 \%$ \\
\hline 7 & $81-90$ & 15 & $10 \%$ \\
\hline 8. & $91-100$ & 04 & $04 \%$ \\
\hline
\end{tabular}

Table 2 shows that $65 \%$ patients were males.

Gender distribution

\begin{tabular}{|l|c|c|}
\hline Sex & No.of cases & Percentage(\%) \\
\hline Male & 65 & $65 \%$ \\
\hline Female & 35 & $35 \%$ \\
\hline
\end{tabular}

Table 3 shows that Left side was involved in majority of cases.

Case Distribution as per side affected

\begin{tabular}{|l|c|c|c|}
\hline S.No. & Fracture side & No.of cases & Percentage(\%) \\
\hline 1. & Right & 47 & $47 \%$ \\
\hline 2. & Left & 53 & $53 \%$ \\
\hline
\end{tabular}

Table 4 shows that $52 \%$ patients reported due to Trivial trauma to hip.

Case Distribution as per mode of injury.

\begin{tabular}{|l|c|c|c|}
\hline S.No & Mechanism of injury & No.of cases & Percentage(\%) \\
\hline 1. & Trivial trauma & 52 & $52 \%$ \\
\hline 2. & Fall from height & 25 & $25 \%$ \\
\hline 3. & RTA & 23 & $23 \%$ \\
\hline
\end{tabular}

Table 6 shows that $18 \%$ of cases had associated injuries

Cases with associated injuries

\begin{tabular}{|l|c|c|}
\hline Associated injury & No. of cases & Percentage(\%) \\
\hline Fracture DER & 05 & $5 \%$ \\
\hline Fracture olecranon & 04 & $4 \%$ \\
\hline Fracture clavicle & 01 & $1 \%$ \\
\hline Fracture femur & 03 & $3 \%$ \\
\hline Head injury & 02 & $2 \%$ \\
\hline Fracture tibia & 01 & $1 \%$ \\
\hline Fracture humerus & 02 & $2 \%$ \\
\hline
\end{tabular}

Table 7 shows Out of 100 patients 53 patients had systemic diseases.

Associated Medical problems

\begin{tabular}{|l|c|c|}
\hline Associated diseases & No.of cases & Percentage(\%) \\
\hline Diabetes Mellitus & 15 & $15 \%$ \\
\hline Hypertension & 26 & $26 \%$ \\
\hline COPD & 06 & $06 \%$ \\
\hline HIV Infected & 01 & $01 \%$ \\
\hline Addiction(alcohol) & 3 & $03 \%$ \\
\hline Psychirtric illness & 2 & $02 \%$ \\
\hline $\begin{array}{l}\text { Patients with no } \\
\text { associated disease }\end{array}$ & 47 & $47 \%$ \\
\hline
\end{tabular}

\section{Discussion}

Intertrochnteric Fractures of femur occur as a low energy trauma in elderly patients and high energy trauma in young patients. The high prevalence of these fractures in elderly is related to various factors including malnutrition, decreased physical 
activity, poor balance, impaired vision, neurological impairment and muscular weakness. Mean age of patients in our study was 74.77 years. This is significantly lower compared to study of Bolhofner et al which recorded mean age as 79 and Alobiad et al in which mean age was 81 years. In our study $65 \%$ patients were males and 35\% were females signifying men being more exposed to risk factors and more active on account of occupation. Left side was involved in $53 \%$ of patients compared to right side. In terms of mechanism of injury $52 \%$ of fractures were caused by trivial fall followed by fall from height (25\%) and road traffic accident (23\%).18\% of cases had associated injuries with fracture of distal radius and fracture olecranon compromising $05 \%$. The associated medical problems were studied. Out of 100 patients 53 patients had systemic diseases. Hypertension being most common associated medical problem (26\%) followed by diabetes milletus (15\%) and COPD (6\%).The associated medical problems are leading causes of deaths in elderly with intertrochanteric fractures. They have increased risk during anesthesia. These problems need to be assessed and require adequate treatment. Intertrochanteric fractures are associated with marked morbidity and mortality. Van Balen reported 20\% mortality in their study (Van Balen et al, 2011)

\section{Conclusion}

From this study we concluded that intertrochanteric fractures are relatively common in our environment with higher incidence seen in elderly above 60 years of age. Intertrochanteric fractures are seen with increasing number and severity as the life expectancy of our population is increasing. The primary goal in the treatment of intertrochanteric fractures is to return the patient to his/ her pre-fracture activity as early as possible. Early mobilization of these patients reduces the morbidity and mortality rate. Fracture fixation is not the final treatment but actually it is beginning of treatment which includes decreasing the incidence of hip fractures, educate elderly about bone health and healthcare programmes.

\section{References}

1. Alobaid A, Harry EJ,Elder GM Prospective randomized trial of two techniques of insertion of a standard dynamic fixation device. $\mathbf{J}$ orthop Trauma 18(4):207-212

2. A.O; Orthopedic trauma association committee for coding and classification Fracture and dislocation Compendium; J Orthop trauma 1996; 10(1); 30-35.

3. Bolhofer, Brett R, Russo, Paul R. Results of intertrochanteric fracture treated with a 135 degree sliding screw with a 2 holed side plate; Journal of orthopaedic trauma, jan 1999; 13(1): 5-8

4. Boyd and griffin. Classification and treatment of trochanteric fractures; Arch surg ; 1949;58: 853-866.

5. Dretakis OE, Margioris AN, Tsatsanis Dretakis KE ,Malliaraki N, Steriopoulus K .Elderly patients with trochanteric hip fractures have lower serum vitamin D3 levels compared to patients with cervical hip fractures. Arch Gerontol Geriatr 2011;52: e15-8.

6. Evans E. The treatment of trochanteric fractures of femur J bj s 1949; 191:53-63.

7. Greenspan SL, Myers ER ,Maitland LA,Kido TH,Krasnow MB, Hayes WC. Trochamteric bone mineral density is associated with type of hip fracture in the elderly.J Bone Miner Res 1994;9:1889-94.

8. Grisso JA, Kelsey JL,Strom BL,Chiu GY, Maislin G,O'Brien LA, Hoffman S, Kaplan F.Risk factors for falls as a cause of hip fracture in women.The Northeast Hip Fracture study group.N Engl J Med.1991;324:1326-1331.

9. Johnell O, Kanis JA, Oden A, Johansson $\mathrm{H}$, de laet C, Delmas $\mathrm{P}$, et al, Predictive value of BMD for hip and other fractures. J Bone MinerRes 2005:20:1185 -94. 
10. Kesmezacar H, Ayhan E, Unlu MC, Seker A, Karaca S. Predictors of mortality in elderly patients with an intertrochanteric or femoral neck fracture .J Trauma.2010;68 (1):153-158.

11. Rockwood c, Green D, Bucholz R. Rockwood and Green' fractures in adults, Philadelphia: Lippincott Williams \& Wilkins;2006.

12. Van Balen R, Steyerberg EW, Polder JJ, Ribbers TL, Habbema JD, Cools HJ. Hip fractures in elderly patients : outcomes for function, quality of life and type of residence Clin Orthop Relat Res.2110;390:232-243. 